\title{
O ENSINO-APRENDIZAGEM DA RELACCÃO TRIGONOMÉTRICA NOS TRIÂNGULOS RETÂNGULOS
}

\author{
Apresentação: Comunicação Oral \\ Erivaldo Gumercindo de Souza Neto ${ }^{1}$; Giselly de Oliveira Silva ${ }^{2}$; Aguinalda Alves Teixeira \\ Filha $^{3}$ Ana Patrícia Siqueira Tavares Falcão ${ }^{4}$; Moacyr Cunha Filho ${ }^{5}$
}

\begin{abstract}
Resumo
Os conceitos trigonométricos apresentam uma relevante importância para o ensino e aprendizado da Geometria, no entanto, esse aprendizado exige cada vez mais sacrifício, devido às dificuldades que os alunos apresentam mediante a compreensão do conteúdo, dificuldades também enfrentadas pelos professores que alegam ser um conteúdo difícil para aplicar uma metodologia alternativa. O estudo da trigonometria é realizado pelo homem desde a antiguidade. O ensino-aprendizagem da trigonometria é caracterizado pelos estudantes como sendo cansativo, repetitivo e desestimulante. Estudos como este são de suma importância para a Educação Matemática, pois a partir dele é possível identificar como está se dando o ensino-aprendizagem da trigonometria em triângulos retângulos no Ensino Fundamental, e reconhecer se há falhas do sistema educacional, investigando as dificuldades encontradas por professores e estudantes do atual cenário da educação pública. O estudo tem como objetivo identificar como ocorre o ensino-aprendizagem da relação trigonométrica nos triângulos retângulos no nono ano do Ensino Fundamental de uma escola pública. Trata-se de uma pesquisa de campo com abordagem Quali-Quantitativa. Participaram do estudo 34 estudantes e 16 professores de Matemática do Ensino Fundamental. Os estudantes responderam a um questionário contendo 6 questões e os professores um contendo, 4 questões referentes ao ensino de trigonometria. Todos os alunos afirmaram não saber o objetivo de estudo da trigonometria. A partir do estudo é possível concluir que o ensino-aprendizagem da trigonometria em triângulo retângulo, merece uma maior atenção por parte dos professores, que podem usar diversos recursos como, jogos, softwares, a história entre outros, a fim de auxiliar nesse processo.
\end{abstract}

Palavras-Chave: ensino-aprendizagem, ensino fundamental, triângulos, trigonometria

\section{Introdução}

Os conceitos trigonométricos apresentam uma relevante importância para o ensino e aprendizado da Geometria, no entanto, esse aprendizado exige cada vez mais sacrifício, devido às dificuldades que os alunos apresentam mediante a compreensão do conteúdo, dificuldades também enfrentadas pelos professores que alegam ser um conteúdo difícil para aplicar uma metodologia alternativa.

A matemática é encontrada e vivenciada no cotidiano, seu uso diário é indispensável, por isso, se faz necessário que os estudantes relacionem e percebam a participação da

\footnotetext{
${ }^{1}$ Mestrado em Estatística, Universidade Federal Rural de Pernambuco, dinhosax14@hotmail.com

${ }^{2}$ Licenciatura em Química, Instituto Federal de Pernambuco - Campus Vitória de Santo Antão, quimicagiselly@gmail.com

3 Docente, Instituto Federal de Pernambuco - Campus Vitória de Santo Antão, aguinalda.alves@vitoria.ifpe.edu.br

${ }^{4}$ Docente, Instituto Federal de Pernambuco - Campus Vitória de Santo Antão, ana.falcao@vitoria.ifpe.edu.br

${ }^{5}$ Doutor em Agronomia, Universidade Federal Rural de Pernambuco, moacyr@deinfo.ufrpe.br
} 
matemática nas diferentes ocorrências do dia a dia, cabe ao professor orientar e trabalhar com os alunos para que eles possam identificar a presença e a importância da Matemática em suas vidas, a partir dessa etapa fica mais fácil o aluno se interessar pela matemática, após perceber que aquilo que ele estudou em sala de aula é importante para muitas situações que estão acontecendo fora do ambiente escolar.

Desenvolver um contexto por fundamentos matemáticos faz com que o aluno enriqueça seu conhecimento a respeito das situações que podem ser encontradas e observadas na sua vida social e vinculada com a interdisciplinaridade podendo ser aplicada em outras ciências.

Acredita-se que no ensino-aprendizagem da trigonometria em triângulos retângulos no Ensino Fundamental ocorra falhas e a não utilização de recursos didáticos a fim de auxiliar no processo de aprendizagem, assim como práticas educacionais contrárias às sugeridas pelos Parâmetros Curriculares Nacionais (1997).

Estudos como este são de suma importância para a Educação Matemática, pois a partir dele é possível identificar como está se dando o ensino-aprendizagem da trigonometria em triângulos retângulos no Ensino Fundamental, e reconhecer se há falhas do sistema educacional, investigando as dificuldades encontradas por professor e estudantes do atual cenário da educação pública.

O estudo tem como objetivo identificar como está ocorrendo o ensino-aprendizagem da relação trigonométrica nos triângulos retângulos no nono ano do Ensino Fundamental de uma escola pública de Vitória de Santo Antão-PE.

\section{Fundamentação Teórica}

A trigonometria segundo Ledur, Enriconi e Seibert (2001), surgiu com a necessidade de resolver problemas relativos à Astronomia, à Navegação, à Cartografia e à Topografia, tem como um dos seus principais objetivos "estudar as relações entre os lados e os ângulos de um triângulo", como também o de estabelecer ou demarcar seus territórios, que chamamos de agrimensuras podendo assim observar o surgimento da análise e da álgebra.

Os primeiros indícios de Trigonometria surgiram, tanto no Egito quanto na Babilônia, a partir dos cálculos de razões entre números e entre lados de triângulos semelhantes (FELIX, 2011). O desenvolvimento da trigonometria está ligado ao da geometria. Thales (625 - 546 a.C.), com seus estudos de semelhança que embasam a trigonometria, e seu discípulo 
Pitágoras (570 - 495 a.C.), conjectura-se que este último tenha feito a primeira demonstração do teorema que leva seu nome: em todo triângulo retângulo a área do quadrado construído sobre a hipotenusa é igual à soma das áreas dos quadrados construídos sobre os catetos. Deste teorema deriva a relação fundamental da trigonometria (NIELCE; LOBO, 2003).

Os Babilônios tinham interesse na Astronomia, por razões religiosas e pelas conexões no calendário e nas épocas de plantio, como eram excelentes astrônomos, elaboraram um calendário astrológico e uma tábua de eclipses lunares, este calendário e esta tábua chegaram até os dias atuais (SMITH, 1958).

Considerado como um marco na história da trigonometria, conhecido como sendo o pai da trigonometria, Hiparco de Nicéia (180-125 a.C.), influenciado pela matemática da Babilônia, dividiu cada arco de $1^{\circ}$ em 60 partes obtendo o arco de 1 minuto. Sua trigonometria baseava-se em uma única "função", na qual a cada arco de circunferência de raio arbitrário, era associada à respectiva corda. Hiparco construiu o que foi presumivelmente a primeira tabela trigonométrica com os valores das cordas de uma série de ângulos de $0^{\circ} \mathrm{a}$ $180^{\circ}$, em cuja montagem utilizou interpolação linear (NIELCE; LOBO, 2003).

O estudo da trigonometria é pouco explorado dentro do dia a dia do aluno. Na maioria das vezes utiliza-se fórmulas e exige-se memorizações de relações sem assemelhar a qualquer sentido ou significado (BRIGUENTI, 2007; CAMARGO, 2004).

Em relação ao ensino da trigonometria Nacarato et al. (2009) apontam que a ênfase que se dá ao seu ensino, nos dias atuais, está pautada em exercícios procedimentais e, raramente, em problemas de aplicação. Pouca ou quase nenhuma ênfase é dada à formação de conceitos.

A Trigonometria é um conteúdo sempre presente no Ensino Médio, com grande aplicabilidade na Física e na própria Matemática e com muitas páginas de livros didáticos dedicadas a esse assunto. No entanto, nem sempre os alunos se sentem motivados para seu estudo, apresentando dificuldades na resolução de problemas que envolvem as relações e funções trigonométricas. Uma das maneiras de auxiliar os estudantes na aprendizagem de Trigonometria consiste em mostrar aplicações dos conteúdos em situações da vida cotidiana, com apoio de materiais manipuláveis (SANTOS; CURY, 2011, p. 50).

Para Varandas (2003), o uso desses recursos traz significativas contribuições para o processo de ensino e aprendizagem de Matemática à medida que relativiza a importância do cálculo mecânico e da simples manipulação simbólica. 


\section{Metodologia}

A metodologia adotada neste trabalho tem uma abordagem quali-quantitativa, do tipo descritiva de campo. Quantitativa por necessitar expor os dados obtidos em tabelas e gráficos, exigindo um número significativo de alunos para garantir maior precisão nos resultados que serão projetados para o conteúdo em questão e através de informações, que foram coletados por meio de um questionário estruturado com perguntas claras, objetivas e discursivas.

Qualitativa, pois estimula os estudantes a pensarem e falarem livremente sobre as questões propostas, fazendo emergir aspectos subjetivos, atingindo motivações não explícita, ou mesmo não conscientes de forma espontânea.

O estudo teve como sujeitos 34 (trinta e quatro) estudantes do $9^{\circ}$ ano do Ensino Fundamental, e 16 (dezesseis) professores de Matemática que lecionam no Ensino Fundamental de diferentes escolas da Zona da Mata de Pernambuco.

Aos estudantes, foi aplicado um questionário com 6 (seis) perguntas, sobre o ensinoaprendizagem da trigonometria estruturado com base no que defende os PCN (1997). Aos professores foi aplicado um questionário contendo 4 (quatro) questões referentes ao ensino de trigonometria, como ocorre a introdução do conteúdo, a avaliação entre outras.

\section{Resultados e Discussão}

Quando questionados sobre dificuldades com a trigonometria, 67,64\% (23) dos estudantes afirmaram ter apresentado dificuldades na aprendizagem de trigonometria em triângulos retângulos. Na segunda questão, 52,94\% (18) dos estudantes informaram ter ideia sobre onde a trigonometria pode ser aplicada.

Quando questionados sobre se durante as aulas de trigonometria havia resoluções de problemas relacionados a aplicação no cotidiano, 58,82\% (20) informaram que sim. 82,35\% (28) dos alunos alegaram não conhecer a história da trigonometria.

Oliveira e Morey (2004) defendem o uso da história como recurso didático no processo de ensino-aprendizagem, os autores alegam que existem então, três categorias de pessoas que normalmente se defrontam ou se defrontaram com situações como as descritas anteriormente: o inventor, o historiador e o estudante. O inventor de uma técnica ou aplicação usa as informações que herdou para arranjas maneiras mais eficazes de responder a velhas questões ou colocar e responder as novas. O historiador procura recompor através de textos e 
artifícios os processos mentais do inventor, sendo nesse caso o seu enfoque limitado pelas suas concepções pessoais. E finalmente temos o estudante para o qual um determinado problema é tão novo quanto já foi para o inventor.

Apenas, 20,58\% (7) informaram já ter utilizado recursos tecnológicos para aprender trigonometria. Apenas, 35,9 (12) alegaram já terem utilizados jogos com a finalidade de estudar a trigonometria.

Para Piva et al. (2010) o computador não deve ser visto como uma máquina que ensine e administre esse ensino e que venha apenas facilitar a atividade do professor, isso significa dizer que a análise de um sistema computacional com finalidades educacionais não pode ser feita sem considerar o seu contexto pedagógico de uso.

Gráfico 1. Respostas dos estudantes referentes as perguntas de 1 a 7, Vitória de Santo Antão, 2014. Fonte: Própria.

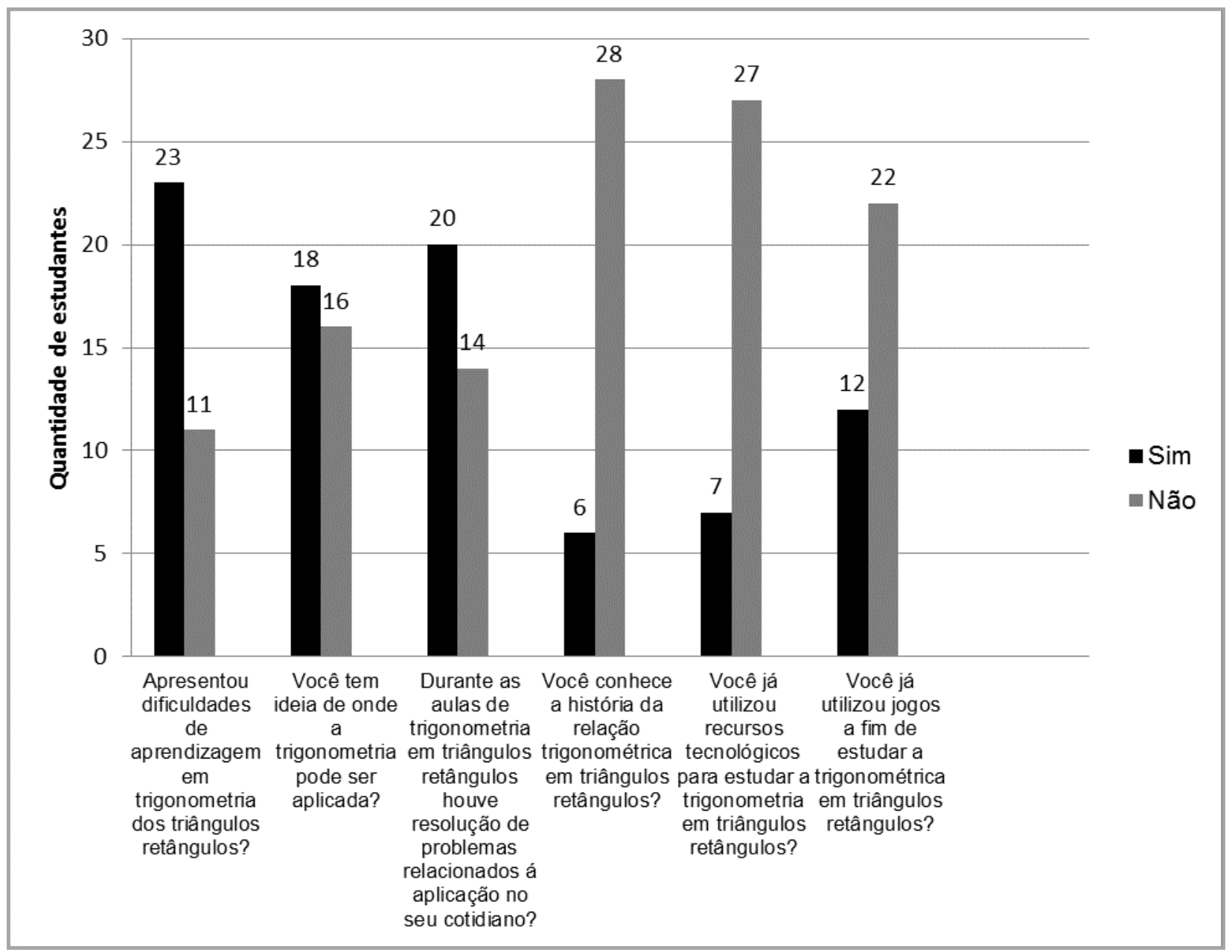


A partir do gráfico 1 é possível perceber que a maior parte dos alunos sentem dificuldades em trigonometria e que esta variável pode está relacionada com a falta de utilização de recursos didáticos como a utilização da história da trigonometria, a utilização da tecnologia e jogos lúdicos.

Os PCN's (1997) sugerem a utilização de alguns recursos didáticos para facilitar o ensino-aprendizagem da Matemática, ressalvando que não há uma fórmula única de obter melhores resultados nesse processo, no entanto algumas ferramentas podem ser utilizadas a fim de amenizar os obstáculos. Podendo o professor recorrer à resolução de problemas, à História da Matemática, às tecnologias da informação e aos Jogos.

Tabela 1. Respostas dos professores referentes ao ensino da trigonometria, Vitória de Santo Antão, 2014. Fonte: Própria.

\begin{tabular}{|l|c|c|c|c|}
\hline \multicolumn{1}{|c|}{ Pergunta } & Sim & \% & Não & \% \\
\hline $\begin{array}{l}\text { Ao iniciar o conteúdo de } \\
\text { trigonometria, você costuma fazer } \\
\text { um apanhado histórico? }\end{array}$ & 10 & 62,5 & 06 & 37,5 \\
\hline $\begin{array}{l}\text { Você sabe os objetivos de estudo } \\
\text { da trigonometria? }\end{array}$ & 00 & 00 & 16 & 100 \\
\hline $\begin{array}{l}\text { Em suas aulas de trigonometria, } \\
\text { você costuma relacionar o } \\
\text { conteúdo com o cotidiano dos seus } \\
\text { alunos? }\end{array}$ & 03 & 18,75 & 13 & 81,25 \\
\hline $\begin{array}{l}\text { Você identificou dificuldades no } \\
\text { processo ensino - aprendizagem da } \\
\text { trigonometria? }\end{array}$ & 13 & 81,25 & 03 & 18,74 \\
\hline
\end{tabular}

A partir da tabela 1 percebe-se o déficit de informações que os professores apresentam em relação aos objetivos de estudo da trigonometria, é muito comum os professores não discutir um pouco sobre o conteúdo a ser trabalhado indo direto para a explicação do assunto, deixando assim lacunas referentes a importância e aplicação do conteúdo abordado no cotidiano do aluno.

Para Oliveira (2006) a maior dificuldade enfrentada pelos professores baseia-se na falta de tempo que o mesmo tem para elaborar as atividades, a maioria dos professores tem mais de um emprego. Assim, acaba sendo mais viável preparar aulas expositivas e exercícios de fixação pois estes gastam menos tempo do que elaborar atividades com matérias manipuláveis.

Poucos professores afirmaram fazer relação do conteúdo abordado com o dia a dia do estudante, dificultando assim a aprendizagem. Para Luccas e Batista (2008) a contextualização dos objetos matemáticos pode estimular os alunos para que se sintam 
motivados a aprender, principalmente quando envolve um contexto diferente do puramente matemático tão enfatizado pela perspectiva formalista.

\section{Conclusões}

A partir do presente estudo, foi possível concluir que as dificuldades encontradas pelos alunos e pelos professores do $9^{\circ}$ ano do ensino fundamental em relação ao ensinoaprendizagem das relações trigonométricas nos triângulos retângulos, encontram-se divididas em três momentos, ou seja, na da definição do conteúdo, na parte algébrica e geométrica e na forma que o docente trabalha e avalia tais conteúdos.

Desta forma, é possível perceber que as dificuldades de aprendizagem são muitas vezes provenientes de uma certa deficiência no ensino e na falta de uma metodologia adequada para trabalhar com conteúdo básicos da trigonometria, dificultando a aprendizagem dos alunos.

O estudo da matemática exige o "acúmulo de bagagem" de conhecimentos matemáticos que o estudante precisa trazer desde as séries inicias, quando isso não acontece fica difícil compreender o conteúdo a ser estudado, fazendo necessário o professor fazer uma breve revisão dos assuntos necessários para o entendimento dos futuros conteúdos.

\section{Referências}

BRASIL. Secretaria de Educação Fundamental. Parâmetros Curriculares Nacionais: Matemática. Secretaria de Educação Fundamental. Brasília: MEC/SEF, 1997.

BRIGUENTI, M. J. L. Ensino e aprendizagem da trigonometria: novas perspectivas da educação matemática. 1994. Dissertação de Mestrado, UNESP, Rio Claro, 1994. Disponível em: http://www.proem.pucsp.br/teses/Briguen.html. Acesso em: 03 dez 2007.

CAMARGO, S. N. Ensino com enfoque na pesquisa: repercussões na aprendizagem de trigonometria. 2004. 122 p. Dissertação (Mestrado em Educação em Ciências e Matemática). Faculdade de Física, PUCRS, Porto Alegre, 2004.

FELIX, D. D. História da Trigonometria: Um levantamento dos trabalhos produzidos nos cursos de especialização e graduação do Departamento de Matemática. 2011. 45 p. Monografia (Licenciatura em Matemática). Departamento de Matemática do Centro de Ciências e Tecnologias. Universidade Estadual da Paraíba, Campina Grande, 2011.

LEDUR, B. S.; ENRICONI, M. H. S.; SEIBERT, T. E. Trigonometria: por meio de construção de conceitos. São Leopoldo: UNISINOS, 2001.

LUCCAS, S.; BATISTA, I. L. A importância da contextualização e da descontextualização no Ensino de Matemática: uma análise epistemológica. 2008. In: ENCONTRO BRASILEIRO 
DE ESTUDANTES DE PÓS-GRADUAÇÃO EM EDUCAÇÃO MATEMÁTICA. 7, 2008, Rio Claro. Anais... São Paulo, 2008. Disponível: http://www2.rc.unesp.br/eventos/matematica/ebrapem2008/upload/205-1-A-

Microsoft\%20Word\%20-\%20gt2_luccas_ta.pdf. Acesso em: $02 \mathrm{dez} 2014$.

NACARATO, A. M.; BREDARIOL, C. C.; PASSOS, M. P. F. Trigonometria: uma análise da sua evolução histórica e da transposição didática desse conhecimento presente nos manuais didáticos e propostas curriculares. 2009. Disponível em: http://nutes2.nutes.ufrj.br/interage/download2.php?file=../arquivos/sitprob/CPC/trigonometria umaanalise.pdf. Acesso em: 27 out 2014.

NIELCE, M. L. C. História da Trigonometria. Educação Matemática em Revista. n.10, p. 60-68, 2003.

OLIVEIRA, F. C.; MOREY, B. B. História da Matemática nas aulas de trigonometria. In: ENCONTRO NACIONAL DE EDUCAÇÃO MATEMÁTICA, 8., 2004, Recife. Anais... Recife: ENEM, 2004. p. 1-7.

OLIVEIRA, F. C. Dificuldades no processo ensino aprendizagem de trigonometria por meio de atividades. 2006, p. 74. Dissertação (Mestrado em Ensino de Ciências Naturais e Matemática) - Universidade Federal do Rio Grande do Norte, Natal, 2006.

PIVA, C.; DORNELES, L. D.; SPILIMBERGO, A. P. Utilizando softwares livres para explorar conceitos de trigonometria. In: ENCONTRO NACIONAL DE EDUCAÇÃO MATEMÁTICA, 10., 2010, Salvador. Anais...Salvador: SBEM, 2010. p. 1-10.

SMITH, D.E. History of Mathematics. Dover Publications. New York, 1958.

SANTOS, D. C.; CURY, H. N. O uso de materiais manipuláveis como ferramenta na resolução de problemas trigonométricos, Santa Maria, Vidya, v. 31, n. 1, p. 49-61, jan/jun, 2011. 